\title{
Tele-Ophthalmology Practices and Attitudes in the Philippines in Light of the COVID-19 Pandemic: A Survey
}

This article was published in the following Dove Press journal: Clinical Ophthalmology

\author{
Corrina P Azarcon (1D) \\ Felice Katrina T Ranche ${ }^{1,2}$ \\ Darby E Santiago ${ }^{1,2}$ \\ 'Department of Ophthalmology and \\ Visual Sciences, Philippine General \\ Hospital, University of the Philippines - \\ Manila, Manila, Philippines; ${ }^{2}$ College of \\ Medicine, University of the Philippines - \\ Manila, Manila, Philippines
}

Background: The Severe Acute Respiratory Syndrome Coronavirus 2 (COVID-19) pandemic has limited patient access to out-patient care, prompting many clinicians to incorporate telemedicine in their practice. This study aims to explore the impact of the pandemic on the use of tele-ophthalmology in the Philippines.

Methodology: A 30-item online survey on practices and attitudes related to teleophthalmology was sent to ophthalmologists and ophthalmologists-in-training all over the Philippines.

Results: A total of 327 local ophthalmologists responded to the anonymous survey. Reported use of tele-ophthalmology increased from $53 \%$ to $90 \%(P<0.001)$ at the time of the COVID-19 pandemic. Social media messaging was the most employed modality, utilized by 8 out of 10 tele-ophthalmology users. Respondents reported confidence in diagnosing gross conditions of the eye, and lack of confidence in diagnosing posterior pole conditions and orbital fractures. The majority $(84 \%)$ believe that it can be adopted on a wider scale in the upcoming years.

Conclusion: The pandemic catalyzed a nationwide increase in the utilization of teleophthalmology. The majority of respondents expressed willingness to continue incorporating tele-ophthalmology in their practice after the pandemic.

Keywords: tele-ophthalmology, telemedicine, coronavirus, attitudes, survey

\section{Introduction}

Technology for telemedicine has been available since the mid-20th century. Its potential to improve healthcare access has been recognized for several decades; however, the much-awaited increase in its utilization is yet to be observed. ${ }^{1}$ In the field of ophthalmology, telemedicine is considered among the most promising solutions to address inadequate access to eye care practitioners in rural communities. $^{2-4}$

In a 2007 survey conducted among various medical specialists in the United States, 18 of 18 ophthalmologists who responded reported that they did not engage in telemedicine. Among the reasons identified for the non-use of telemedicine across different specialties were: difficulty or inconvenience in accessing necessary equipment, unreliable technology, time-consuming nature, inadequate or unavailable reimbursement, and non-equivalence to in-person consults. ${ }^{1}$ In 2015, Woodward et al conducted a survey to assess the attitudes of eye care physicians towards tele-ophthalmology. Respondents displayed varying attitudes and opinions
Correspondence: Corrina P Azarcon Department of Ophthalmology and Visual Sciences, Philippine General Hospital, University of the Philippines - Manila, Sentro Oftalmologico Jose Rizal Building, Taft Avenue, Ermita, Manila, I000 Philippines

Email corrinaa.md@gmail.com 
regarding the feasibility of the telemedicine integration in routine clinical practice. Non-users of telemedicine were more likely than users to claim that a live interaction was necessary to ensure completeness of the examination. However, the majority of the survey respondents reported willingness to use telemedicine applications for requesting consultations, receiving consultations, and interpreting photographs. Although many were not confident in existing telemedicine applications at the time of the survey, the majority still believed that the role of tele-ophthalmology would be greater in the coming years. The study recommended the development of validated telemedicine protocols for the management of eye diseases. ${ }^{4}$

Data on Philippine tele-ophthalmology is scarce. Camara and Rodriguez reported the use of real-time telementoring for endoscopic laser-assisted dacryocystorhinostomy in 1998. The study concluded that real-time remote monitoring and teaching during ophthalmic surgeries was possible using technology existing at that time. ${ }^{5}$ In 2014, Tayapad et al conducted a retrospective, cross-sectional pilot survey of diabetic patients undergoing screening for diabetic retinopathy using a digital fundus camera. The study concluded that the method can successfully identify patients with complications needing further ophthalmologic management. ${ }^{6}$

During recent pandemics and public health emergencies SARS-CoV (severe acute respiratory syndrome-associated coronavirus), MERS-CoV (Middle East respiratory syndrome coronavirus), Ebola, and Zikavirus - telemedicine proved to be valuable. Its most essential roles were in remote triaging, monitoring of cases, and virtual consultations. Shifting from face-to-face outpatient consultations to teleconsultations allowed significant reduction of the patient load at the hospital. ${ }^{7,8}$

A similar need for telemedicine was to be expected during the COVID-19 pandemic. De Lott et al recently published results of a survey conducted among clinicians at the University of Michigan Kellogg Eye Center. This study explored the change in ophthalmic clinicians' attitudes toward telemedicine during the COVID-19 pandemic. Responses demonstrated an increase in the utilization of telemedicine from before to during the pandemic. Many of the clinicians surveyed were at least somewhat confident when using telemedicine during the pandemic. The study also suggested that practice and exposure to telemedicine improved confidence in its use. ${ }^{9}$

The COVID-19 pandemic also caused a major shift in Philippine healthcare. In addition to social distancing and isolation, community quarantines and curfews were imposed on certain territories. These limited mobility across municipal or provincial borders, consequently also limiting access to healthcare. The number of cases and the stringent protocols for treatment overwhelmed the existing healthcare system, with shortages in personal protective equipment, hospital beds, and medical personnel. All of these led to the cessation of many non-COVID-related services, including ophthalmology clinics. For both doctors and patients, telemedicine became one of the few options available for out-patient consultations.

The increased utilization of telemedicine in the Philippines came with a need to review existing data privacy rules governing its use. Medical information is classified as sensitive personal information under the Philippine Data Privacy Act; thus, it is protected by stringent regulations that cover data collection, processing, and storage. The use of third-party providers for telemedicine services requires additional layers of protection such as data sharing agreements and staff dedicated to oversee data privacy concerns. No changes in patient privacy rules were enforced as a response to the pandemic. Furthermore, in the Philippines, professional fees for telemedicine services are generally out-of-pocket expenses for the patients. As of this writing, it is not considered a billable procedure by local medical insurance companies.

This prospective, descriptive study aims to evaluate baseline practices and attitudes of ophthalmologists in the Philippines towards tele-ophthalmology. It also aims to examine changes in these practices and attitudes brought about by the COVID-19 pandemic, so that factors affecting readiness and willingness to adapt teleophthalmology may be discovered and addressed.

\section{Materials and Methods}

This study was approved by the University of the Philippines - Manila Research Ethics Board (UPMREB 2020-355-01).

\section{Sample Selection}

Ophthalmologists and ophthalmologists-in-training practicing in the Philippines were invited to participate in an anonymous online survey. A target of 306 participants was computed with an error rate of $5 \%$ and a confidence interval of $95 \%$. A link to the 30 -item electronic survey form was disseminated over e-mail and various social media platforms over thirty days, beginning July 2020, during a period when nation-wide community quarantine 
measures were in place. Eye, Ear, Nose, and Throat (EENT) specialists were excluded. Retired ophthalmologists, ophthalmologists who shifted to another career, and Filipino ophthalmologists who migrated out of the country were also excluded from the survey.

\section{Survey Instrument}

The first portion of the anonymous self-administered online questionnaire included a consent form which also presented the inclusion and exclusion criteria. The survey consisted of 30 multiple-choice questions about: 1) the general nature of the ophthalmologist's practice; 2) use of tele-ophthalmology before and during the pandemic; 3) plans to utilize tele-ophthalmology after the pandemic; and 4) overall impression about tele-ophthalmology. The survey also included questions regarding the confidence of the participants in diagnosing and treating certain ocular conditions; the list was based on the most frequently seen ophthalmology cases at the University of the Philippines Philippine General Hospital, a tertiary care center and teaching hospital in Manila. Attitudes were measured using 4-point or 5-point Likert scales. A number of questions were patterned after the survey form used by Woodward et al. ${ }^{4}$

\section{Analyses}

General and clinical characteristics of participants were summarized using descriptive statistics. Variables were reported in frequencies and proportions. Differences of frequencies between unpaired and paired groups were compared using the Fisher's Exact/Chi-square test and McNemar test, respectively. All valid data were included in the analysis. Missing variables were neither replaced nor estimated. Null hypothesis was rejected at $0.05 \alpha$-level of significance. STATA 15.0 was used for data analysis.

Responses were stratified according to age, level of training, years of training and practice, area of practice, type of practice, and income range of patients in order to evaluate statistically significant differences across the different groups. Responses of the participants with regards to their utilization of tele-ophthalmology and attitudes towards tele-ophthalmology before, during, and after the COVID-19 pandemic were compared.

\section{Results}

A total of 327 ophthalmologists and ophthalmologists-intraining participated in the survey (Table 1), with the largest proportion of respondents in their thirties (43\%).
Table I Demographic Profile of Respondents $(n=327)$

\begin{tabular}{|l|c|}
\hline & Frequency (\%) \\
\hline Age, years & \\
$23-29$ & $54(16.51 \%)$ \\
$30-39$ & $142(43.43 \%)$ \\
$40-49$ & $61(18.65 \%)$ \\
$50-59$ & $57(17.43 \%)$ \\
60 and above & $13(3.98 \%)$ \\
\hline Level & \\
Consultant & $229(70.03 \%)$ \\
Resident/Fellow & $98(29.97 \%)$ \\
\hline Years of practice & \\
$0-5$ & $138(42.20 \%)$ \\
$6-10$ & $62(18.96 \%)$ \\
II-15 & $35(10.70 \%)$ \\
I6-20 & $34(10.40 \%)$ \\
$>20$ & $58(17.74 \%)$ \\
\hline Location of practice* & \\
National Capital Region & $194(59.33 \%)$ \\
Luzon, outside the National Capital Region & $107(32.72 \%)$ \\
Visayas & $41(12.54 \%)$ \\
Mindanao & $40(12.23 \%)$ \\
\hline Employer & $187(57.19 \%)$ \\
None & $110(33.64 \%)$ \\
Government institution & $128(39.17 \%)$ \\
Private company & \\
\hline Income classification of the majority of patients & \\
High income & $(3.36 \%)$ \\
Middle income & \\
Low income & \\
\hline
\end{tabular}

Note: *Mutually inclusive.

The majority of the respondents were consultants (70\%); the rest were fellows and residents-in-training (30\%). Forty-two percent (42\%) were either trainees or new graduates ( 0 to 5 years of practice). A large percentage of participants reported the National Capital Region or Luzon as a place of practice (59\% and 33\%, respectively). More than half of the respondents were self-employed or engaging in private practice $(57 \%)$. The majority treated patients from the middle socioeconomic class (57\%).

The COVID-19 pandemic brought about an increase in the respondents' willingness to engage in teleophthalmology (Table 2). Two-thirds of respondents stated that they were not willing, or only somewhat willing to engage in tele-ophthalmology prior to the pandemic. In contrast, during the pandemic, two-thirds of the respondents reported moderate to extreme willingness to use tele- 
Table 2 Tele-Ophthalmology Practices in Temporal Relation to COVID-19 Pandemic

\begin{tabular}{|c|c|c|c|c|c|c|}
\hline & Before & During & After & \multicolumn{3}{|c|}{ Pairwise $P$-values } \\
\hline & \multicolumn{3}{|c|}{ Frequency (\%) } & $\boldsymbol{P}_{\mathbf{a}}$ & $P_{\mathrm{b}}$ & $P_{\mathrm{c}}$ \\
\hline \multicolumn{7}{|l|}{$\begin{array}{l}\text { Willingness to engage in tele-ophthalmology } \\
(n=327)\end{array}$} \\
\hline Not at all & $69(21.10 \%)$ & 15 (4.59\%) & 39 (11.93\%) & $<0.001$ & $<0.001$ & $<0.001$ \\
\hline Somewhat & 144 (44.04\%) & $109(33.33 \%)$ & $120(36.70 \%)$ & & & \\
\hline Moderate & 96 (29.36\%) & I5I (46.I8\%) & 131 (40.06\%) & & & \\
\hline Extreme & $18(5.50 \%)$ & 52 (I5.90\%) & 37 (1।.31\%) & & & \\
\hline $\begin{array}{l}\text { Use of tele-ophthalmology as part of practice } \\
(n=327)\end{array}$ & $173(52.91 \%)$ & $293(89.60 \%)$ & $263(80.43 \%)^{* *}$ & $<0.001$ & $<0.001$ & $<0.001$ \\
\hline Modalities of consultation* & {$[N=173]$} & {$[N=293]$} & {$[N=263]$} & & & \\
\hline Short messaging service & $120(69.36 \%)$ & 177 (60.4I\%) & 139 (52.85\%) & $<0.001$ & $<0.001$ & 0.035 \\
\hline Telephone & II 6 (67.05\%) & $194(66.21 \%)$ & 152 (57.79\%) & $<0.001$ & $<0.001$ & 0.001 \\
\hline E-mail & 53 (30.64\%) & $44(15.02 \%)$ & $86(32.70 \%)$ & 0.145 & $<0.001$ & $<0.001$ \\
\hline Social media messaging & 143 (82.66\%) & $250(85.32 \%)$ & 210 (79.85\%) & $<0.001$ & $<0.001$ & $<0.001$ \\
\hline Third party provider & $3(1.73 \%)$ & 69 (23.55\%) & 89 (33.84\%) & $<0.001$ & 0.003 & $<0.001$ \\
\hline People entertained for virtual consultation* & {$[N=173]$} & {$[N=293]$} & {$[\mathrm{N}=263]$} & & & \\
\hline Friends, relatives, acquaintances & $153(88.44 \%)$ & $236(80.55 \%)$ & $213(80.99 \%)$ & $<0.001$ & 0.018 & $<0.001$ \\
\hline Known patients from own clinic & $106(61.27 \%)$ & $243(82.94 \%)$ & 221 (84.03\%) & $<0.001$ & 0.011 & $<0.001$ \\
\hline $\begin{array}{l}\text { New patients who will be able to physically } \\
\text { go to clinic }\end{array}$ & $10(5.78 \%)$ & II 2 (38.23\%) & $104(39.54 \%)$ & $<0.001$ & 0.424 & $<0.001$ \\
\hline $\begin{array}{l}\text { New patients who will not be able to } \\
\text { physically go to clinic }\end{array}$ & $25(14.45 \%)$ & 178 (60.75\%) & $179(68.06 \%)$ & $<0.001$ & 0.832 & $<0.001$ \\
\hline $\begin{array}{l}\text { Fellow physicians referring their patients } \\
\text { (communication with physician only) }\end{array}$ & $92(53.18 \%)$ & $142(48.46 \%)$ & $185(70.34 \%)$ & $<0.001$ & $<0.001$ & $<0.001$ \\
\hline $\begin{array}{l}\text { Fellow ophthalmologists referring their } \\
\text { patients (communication with colleague only) }\end{array}$ & $87(50.29 \%)$ & 90 (30.72\%) & $186(70.72 \%)$ & 0.646 & $<0.001$ & $<0.001$ \\
\hline Purpose of tele-ophthalmology* & {$[N=173]$} & & {$[N=263]$} & & & \\
\hline $\begin{array}{l}\text { Communicate with patients directly for the } \\
\text { purpose of diagnosing and advising patients } \\
\text { through tele-ophthalmology }\end{array}$ & $108(62.43 \%)$ & - & 194 (73.76\%) & - & - & $<0.001$ \\
\hline $\begin{array}{l}\text { Send referrals to fellow ophthalmologists for } \\
\text { opinion }\end{array}$ & III (64.16\%) & - & $211(80.23 \%)$ & - & - & $<0.001$ \\
\hline $\begin{array}{l}\text { Receive referrals from fellow ophthalmologists } \\
\text { for opinion }\end{array}$ & $100(57.80 \%)$ & - & $206(78.33 \%)$ & - & - & $<0.001$ \\
\hline Send and receive eye diagnostic tests & $109(63.01 \%)$ & - & 228 (86.69\%) & - & - & $<0.001$ \\
\hline
\end{tabular}

Notes: Statistical test used: McNemar's test. $\mathrm{Pa}=$ before versus during the COVID-19 pandemic; $\mathrm{Pb}=$ during versus after the COVID-I9 pandemic; $\mathrm{Pc}=$ before versus after the COVID-19 pandemic. Inquiries into the purpose of tele-ophthalmology during the pandemic were omitted in order to explore other pertinent aspects of practice detailed in the succeeding tables. *Mutually inclusive; **Intended use in the future.

ophthalmology. Reported actual use of tele-ophthalmology rose from $53 \%$ before the pandemic to $90 \%$ during the pandemic $(P<0.001)$. Respondents, however, reported less willingness to engage in tele-ophthalmology after the pandemic compared to during the pandemic $(P<0.001)$. This translated to a slightly lower proportion $(80 \%)$ who intended to use the specified tele-ophthalmology modalities after the pandemic $(P<0.001)$.

The top three modalities employed were social media messaging, telephone, and short message service (SMS), with similar proportions of use from before to during the pandemic. The proportion of respondents using e-mail communications for tele-ophthalmology decreased significantly from $31 \%$ to $15 \%$ upon onset of the pandemic, although it is expected to go up to $33 \%$ after the pandemic. In contrast, the use of services offered by third-party providers increased more than ten-fold $(1.7 \%$ to $23.6 \%)$ during the pandemic, and is expected to increase to $34 \%$ once the pandemic resolves. These services range from software development and website maintenance to marketing and processing of fees. Some third-party providers require one- 
time investments while others are paid via monthly or annual subscription fees.

Participants who engaged in tele-ophthalmology during the pandemic entertained more known patients $(61 \%$ to $83 \%$ ) as well as new patients, regardless of ability to physically visit the clinic during the COVID-19 pandemic, compared to baseline. Use of tele-ophthalmology for respondents included sending and receiving referrals, sending and receiving ocular diagnostic tests, and virtual consultations.

Among tele-ophthalmology practices during the COVID-19 pandemic, exchanges of photographs and videos were done more often than live videoconferencing (Table 3). Most cases were assessed as non-urgent. The majority (95\%) of ophthalmologists gave electronic prescriptions.

A large proportion (44\%) of the 293 users of teleophthalmology during the pandemic reported that they were somewhat confident while communicating with patients remotely, whereas $36 \%$ were neutral (neither confident nor unconfident) (Table 4). Only 1\% reported that they were very unconfident in virtual ophthalmologic diagnosis and management during consults with patients. Nearly half of participants who used engaged in teleophthalmology reported that they were somewhat confident when communicating diagnoses with physicians from other specialties (47\%) and with fellow ophthalmologists (52\%). Participants were most confident in diagnosing subconjunctival hemorrhage (88\%), pterygium (84\%), and conjunctivitis $(71 \%)$ remotely (Figure 1$)$. They were least confident in committing to a diagnosis of hypertensive retinopathy $(5 \%)$, glaucoma $(6 \%)$, and orbital fractures $(7 \%)$ over telemedicine. Only $3 \%$ of participants stated that they were not confident in diagnosing any of the listed ophthalmologic conditions over teleophthalmology.

A large proportion (45\%) of the participants expressed that they were only somewhat comfortable with discussing a management plan when communicating with a colleague remotely, even with the benefit of high-resolution photography. Twenty-two percent of the respondents were not comfortable discussing their patient's eye care with another healthcare provider over the phone without having seen the patient in person. The majority $(82 \%)$ of participants believe that tele-ophthalmology is underutilized in the Philippines, and that it can be adopted on a wider scale in the next five years. More than half of the respondents think that
Table 3 Tele-Ophthalmology Practices During the COVID-19 Pandemic

\begin{tabular}{|c|c|}
\hline & Frequency (\%) \\
\hline \multicolumn{2}{|l|}{$\begin{array}{l}\text { Proportion of consults wherein photos and } \\
\text { videos of patients were utilized }(n=293)\end{array}$} \\
\hline More than $2 / 3$ & I55 (52.90\%) \\
\hline $1 / 3$ to $2 / 3$ & 80 (27.30\%) \\
\hline Less than $1 / 3$ & $58(19.80 \%)$ \\
\hline \multicolumn{2}{|l|}{$\begin{array}{l}\text { Proportion of consults wherein live video- } \\
\text { conferencing was employed }(n=293)\end{array}$} \\
\hline More than $2 / 3$ & $50(17.06 \%)$ \\
\hline $1 / 3$ to $2 / 3$ & $36(12.29 \%)$ \\
\hline Less than $1 / 3$ & $207(70.65 \%)$ \\
\hline \multicolumn{2}{|l|}{$\begin{array}{l}\text { Proportion of patients advised to seek urgent } \\
\text { face-to-face consultation }(n=293)\end{array}$} \\
\hline More than $2 / 3$ & $6(2.05 \%)$ \\
\hline $1 / 3$ to $2 / 3$ & 37 (I2.63\%) \\
\hline Less than $1 / 3$ & $250(85.32 \%)$ \\
\hline \multicolumn{2}{|l|}{$\begin{array}{l}\text { Proportion of patients advised to seek face-to- } \\
\text { face consultation at a later time }(n=293)\end{array}$} \\
\hline More than $2 / 3$ & $55(18.77 \%)$ \\
\hline $1 / 3$ to $2 / 3$ & $103(35.15 \%)$ \\
\hline Less than $1 / 3$ & I 35 (46.08\%) \\
\hline \multicolumn{2}{|l|}{ Gave electronic prescriptions $(n=293)$} \\
\hline Yes, for new and old medications & 221 (75.43\%) \\
\hline Yes, for old medications only & 57 (19.45\%) \\
\hline No & $15(5.12 \%)$ \\
\hline
\end{tabular}

personal, medical, technical, and financial concerns need to be improved (Table 5).

Stratification was done to analyze inter-strata differences in responses to questions pertaining to use of teleophthalmology, willingness to engage in tele-ophthalmology, level of comfort in virtual discussion of a case in the presence of high-resolution photography, perceived degree of utilization of ophthalmology, and belief that teleophthalmology can be adopted in a wider scale in the next few years. Stratification according to age revealed that a significantly larger proportion of participants below 40 years of age $(93 \%, \mathrm{n}=196)$ participated in tele-ophthalmology during the pandemic compared to those aged 40 years and above $(82 \%, \mathrm{n}=131)(P=$ 0.02). In addition, use of tele-ophthalmology was significantly greater among trainees $(95 \%, \mathrm{n}=98)$ compared to consultants $(86 \%, \mathrm{n}=229)$ during the pandemic $(P=$ 0.026). No statistically significant differences were seen in responses when comparing participants who have been in practice for 5 years or less $(n=138)$ compared to those 
Table 4 Confidence in Virtual Diagnosis and Management of Ophthalmologic Conditions When Communicating with Patients, Other Physicians, and Other Ophthalmologists

\begin{tabular}{|l|c|c|c|}
\hline Level of Confidence & $\begin{array}{c}\text { When Communicating with } \\
\text { Patients }\end{array}$ & $\begin{array}{c}\text { When Communicating with } \\
\text { Other Physicians }\end{array}$ & $\begin{array}{c}\text { When Communicating } \\
\text { with Other Ophthalmologists }\end{array}$ \\
\hline Very confident & $11(3.75 \%)$ & $9(3.07 \%)$ & $35(11.95 \%)$ \\
Somewhat confident & $128(43.69 \%)$ & $139(47.44 \%)$ & $150(51.19 \%)$ \\
Neutral & $105(35.84 \%)$ & $95(32.42 \%)$ & $78(26.62 \%)$ \\
Somewhat unconfident & $44(15.02 \%)$ & $36(12.29 \%)$ & $24(8.19 \%)$ \\
Very unconfident & $4(1.37 \%)$ & $5(1.71 \%)$ & $1(0.34 \%)$ \\
No answer & $1(0.34 \%)$ & $9(3.07 \%)$ & $5(1.71 \%)$ \\
\hline
\end{tabular}

who have been practicing for more than 5 years $(n=189)$. Significant differences were also not found when responses are stratified by area of practice. Ophthalmologists employed by the government $(n=110)$ and by private companies $(n=30)$ reported greater utilization of tele-ophthalmology compared to those who were self-employed $(\mathrm{n}=187)(93.64 \%$ vs $96.67 \%$ vs $85.03 \%$, $P=0.027$ ). No statistically significant differences were found when comparing responses of ophthalmologists who see low-income patients $(\mathrm{n}=128)$ compared to those who see middle- to high-income patients $(\mathrm{n}=199)$.

\section{Discussion}

This is the first nationwide survey on tele-ophthalmology conducted in the Philippines. Results indicate that the COVID-19 pandemic has catalyzed an increase in utilization of tele-ophthalmology in the country. Participants reported increased willingness to engage in virtual consultations during and after the pandemic, compared to baseline. This finding is similar to the study of De Lott et al, where telemedicine used increased from $30.7 \%$ before the pandemic to $86.2 \%$ during the pandemic. ${ }^{9}$ Social media messaging, in the form of Facebook Messenger, Viber, or Telegram, was the most commonly used modality, followed by telephone and SMS. The increased use of third-party providers to facilitate consultations during the pandemic demonstrates the potential role of these platforms in the future of tele-ophthalmology. In addition to providing an interface to the conduct of the consult, these third-party providers or telemedicine applications offer improved privacy, data security, data management,

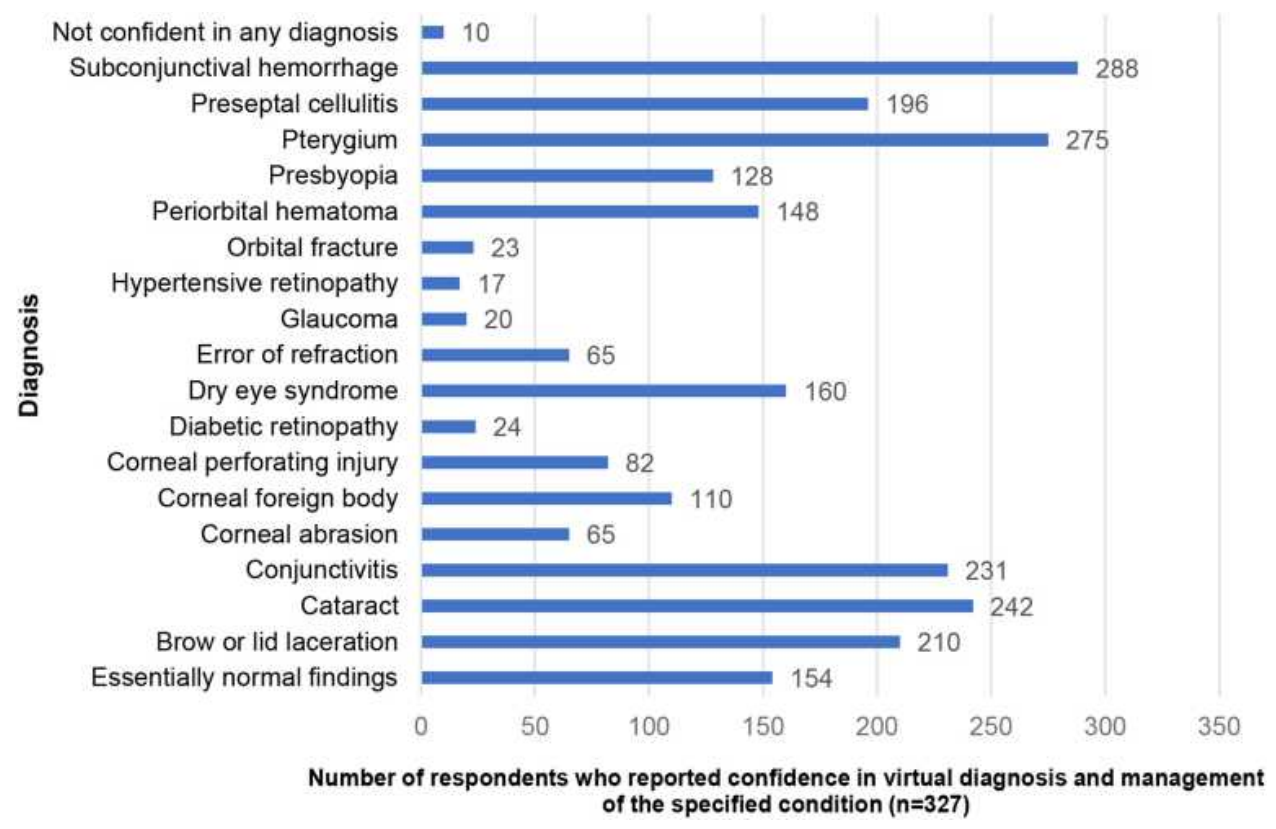

Figure I Confidence in virtual diagnosis and management based on the patient's condition. 
Table 5 Perceptions Regarding Tele-Ophthalmology $(n=327)$

\begin{tabular}{|c|c|}
\hline & $\begin{array}{l}\text { Frequency } \\
\text { (\%) }\end{array}$ \\
\hline \multicolumn{2}{|l|}{$\begin{array}{l}\text { Level of comfort in discussing with colleague over } \\
\text { phone the plan for eye care of a patient not seen in } \\
\text { actual person, given that teleophthalmology and high- } \\
\text { resolution photography are available }\end{array}$} \\
\hline Not at all & $71(21.71 \%)$ \\
\hline Somewhat & $148(45.26 \%)$ \\
\hline Moderate & $96(29.36 \%)$ \\
\hline Extreme & $12(3.67 \%)$ \\
\hline \multicolumn{2}{|l|}{ Overall effect of tele-ophthalmology on practice } \\
\hline Negative & $37(11.31 \%)$ \\
\hline None & $90(27.52 \%)$ \\
\hline Positive & $200(61.16 \%)$ \\
\hline \multicolumn{2}{|l|}{$\begin{array}{l}\text { Perception on degree of utilization of tele- } \\
\text { ophthalmology in the Philippines }\end{array}$} \\
\hline Highly underutilized & $6 \mathrm{I}(18.65 \%)$ \\
\hline Somewhat underutilized & $207(63.30 \%)$ \\
\hline Utilized appropriately & $46(14.07 \%)$ \\
\hline Somewhat overutilized & $12(3.67 \%)$ \\
\hline Highly overutilized & $\mathrm{I}(0.3 \mathrm{I} \%)$ \\
\hline $\begin{array}{l}\text { Believe that tele-ophthalmology can be adopted in } \\
\text { a wider scale in the next } 5 \text { years }\end{array}$ & 276 (84.40\%) \\
\hline \multicolumn{2}{|l|}{ Aspects for improvement } \\
\hline Personal & $232(70.95 \%)$ \\
\hline Medical & 305 (93.27\%) \\
\hline Technical & $25 I(76.76 \%)$ \\
\hline Financial & $174(53.21 \%)$ \\
\hline
\end{tabular}

scheduling, and payment schemes, making them enticing to medical practitioners.

Pre-pandemic, tele-ophthalmology users mostly accepted virtual consultations from friends, relatives, and acquaintances (88\%), known patients from their own clinic (61\%), fellow physicians (54\%), and fellow ophthalmologists $(50 \%)$. Only a minority entertained virtual consults with new patients who would be able to physically go to their clinic (5.8\%) and new patients who would not be able to physically go to their clinic (14\%). The large increase in the proportion of ophthalmologists who accept tele-consultations with both new and known patients $(P<0.001)$ during the pandemic shows the shift from face-to-face consultations to virtual consultations because of restrictions and safety precautions. Results of this study show that reported willingness of the participants to engage in tele-ophthalmology after the pandemic is less compared to reported willingness during the pandemic $(P<0.001)$, indicating that face-to-face consultation is still preferred over virtual consultation.

The majority (53\%) of tele-ophthalmology users during the pandemic reported using videos and photographs as part of their tele-consultation; only a small percentage (17\%) utilized live videoconferences. This may be partly due to connectivity issues, poor video resolution, availability of technology, and privacy issues.

Comparison of advice to seek urgent versus delayed faceto-face consultation shows that most of the tele-consults performed were non-urgent in nature, and that virtual diagnosis and management sufficed for many of them. In addition, nearly all tele-ophthalmology users $(95 \%)$ were able to give electronic prescriptions to their patients, a large proportion of them including new medications.

The confidence of ophthalmologists in committing to diagnoses after remote interview and assessment of patients is an important issue. About 8 to $16 \%$ report to be unconfident with their diagnoses over telemedicine, depending on who they are communicating with. In general, ophthalmologists felt more confident when they were talking to fellow ophthalmologists who were referring patients that they had already seen. It was logical that respondents were generally more confident in diagnosing conditions that could be assessed by gross examination; less confidence was seen in diagnosing fractures (as these require palpation and/or imaging) and conditions of the posterior pole (which require visualization). Teleophthalmology for accurate diagnosis of posterior pole conditions requires the use of instruments such as fundus cameras, and requires patients to report physically at an equipped clinic. ${ }^{6}$ This is a significant limitation especially in rural settings. However, $22 \%$ of respondents reported that, despite access to high-resolution photography, they would still feel uncomfortable with discussing a patient's condition remotely. De Lott et al reported a higher percentage $(33 \%)$ of ophthalmologists and optometrists who expressed that they were not at all confident in using remote screening for eye care. ${ }^{9}$

The acceptance and use of tele-ophthalmology are affected by how ophthalmologists perceive its effects on their practice. In this survey, $61 \%$ believed that it would bring about a positive effect, while only $11 \%$ believed that it would have an overall negative effect. The results are comparable to the report of Woodward et al, where $60 \%$ of ophthalmologists and optometrists surveyed believed that telemedicine would have a positive effect on their practice, 
$20 \%$ believed that it would have a neutral effect, and another $20 \%$ believed that it would result in a negative effect. ${ }^{4}$

Although nearly all participants believed that different aspects of tele-ophthalmology - personal, medical, technical, and financial - still need to be improved, the majority $(84.40 \%)$ agreed that it can be adopted at a wider scale in the next five years. Dedicated telemedicine applications that provide an interface for the consultation while addressing data privacy, data security, data management, scheduling, and payment or reimbursement may prove to be valuable. Integration of tele-ophthalmology into training programs and medical curricula may improve competence and confidence of future ophthalmologists in its use. Lowcost solutions must be explored to maximize the role of tele-ophthalmology in improving access to eye care, especially in areas lacking ophthalmology specialists and subspecialists.

Stratified analysis showed increased utilization of teleophthalmology by ophthalmologists across all age groups during the pandemic, although the proportion of teleophthalmology users is greater among ophthalmologists aged less than 40 . This may reflect the greater adaptability of the younger population to the use of technology. In addition, a greater proportion of trainees compared to consultants practiced tele-ophthalmology during the pandemic. This observation is partly attributed to the need to fulfill the requirements of training. It was also found that governmentemployed and private company-employed ophthalmologists practiced tele-ophthalmology more in comparison to selfemployed ophthalmologists. Lastly, the income bracket of the patients had no effect on the use of tele-ophthalmology. This shows that various modalities of tele-ophthalmology may be utilized to serve patients from different social classes.

There are limitations to the study. First, the nature of sampling may have attracted more volunteers from groups that were more likely to engage in teleophthalmology. Second, as in any survey, the provided answers may differ from the actual practices of the respondents. Third, a minor percentage of the participants provided inconsistent answers with regards to their utilization of tele-ophthalmology. Upon analysis, some of the participants did not consider consultations held via SMS, telephone, or social media messaging applications as actual tele-ophthalmology consults. It is possible that some participants had a different understanding as to what comprises tele-ophthalmology or a tele-consult; however, their understanding of the subject matter was not explored in this study. Lastly, the survey responses were only collected once per participant over a onemonth data collection period. Any further changes in the practices and attitudes of participants brought about by the prolonged course of the pandemic may not be reflected in this study.

\section{Conclusion}

The COVID-19 pandemic catalyzed the use of telemedicine across all medical specialties, including ophthalmology. Although several aspects of its use still need to be addressed, the majority believe that its use can be adapted on a wider scale in the next few years. In developing countries like the Philippines, focus must be given on the development of low-cost technology that can improve access to eye care in areas with no specialists.

\section{Funding}

The authors received no financial support for the conduct and publication of this study.

\section{Disclosure}

The authors report no conflicts of interest for this work and declare no potential conflicts of interest in relation to the conduct and publication of this study.

\section{References}

1. Barton PL, Brega AG, Devore PA, et al. Specialist physicians' knowledge and beliefs about telemedicine: a comparison of users and nonusers of the technology. Telemed J E Health. 2007;13(5):487-499. doi:10.1089/tmj.2006.0091

2. Higginbothan EJ. The physician workforce discussion revisited. Arch Ophthalmol. 2015;130(5):648-649.

3. Lee PP, Hoskins D. PDI. Access to care: eye care provider workforce considerations in 2020. Arch Ophthalmol. 2007;125(3):406-410. doi:10.1001/archopht.125.3.406

4. Woodward MA, Ple-plakon P, Blachley T, et al. Eye care providers' attitudes towards tele-ophthalmology. Telemed J E Health. 2015;21 (4):271-273. doi:10.1089/tmj.2014.0115

5. Camara J, Rodriguez R. Real-time telementoring in ophthalmology. Telemed J. 1998;4(4):375-377. doi:10.1089/tmj.1.1998.4.375

6. Tayapad JB, Bengzon AU, Valero SO, et al. Implementation and pilot data on diabetic retinopathy in a teleophthalmology program at a multispecialty primary care clinic. Philipp $J$ Ophthalmol. 2014;39:90-93.

7. Ohannessian R, Duong TA, Odone A, et al. Global telemedicine implementation and integration within health systems to fight the COVID-19 pandemic: a call to action. JMIR Public Heal Surveill. 2020;6(2):4-9. doi:10.2196/18810

8. Ohannessian R. Telemedicine: potential applications in epidemic situations. La Rech Eur en Télémédecine. 2015;4(3):95-98. doi:10.1016/j.eurtel.2015.08.002

9. De Lott LB, Newman-casey PA, Lee PP, et al. Change in ophthalmic clinicians' attitudes toward telemedicine during the coronavirus 2019 pandemic. Telemed J E Health. 2020;1-6. doi:10.1089/ tmj.2020.0222 


\section{Publish your work in this journal}

Clinical Ophthalmology is an international, peer-reviewed journal covering all subspecialties within ophthalmology. Key topics include: Optometry; Visual science; Pharmacology and drug therapy in eye diseases; Basic Sciences; Primary and Secondary eye care; Patient Safety and Quality of Care Improvements. This journal is indexed on PubMed

Submit your manuscript here: https://www.dovepress.com/clinical-ophthalmology-journal
Central and CAS, and is the official journal of The Society of Clinical Ophthalmology (SCO). The manuscript management system is completely online and includes a very quick and fair peer-review system, which is all easy to use. Visit http://www.dovepress.com/ testimonials.php to read real quotes from published authors. 